\title{
A mathematical model for in vitro coagulation of blood: role of platelet count and inhibition
}

\author{
M SUSREE and M ANAND* \\ Department of Chemical Engineering, Indian Institute of Technology Hyderabad, Kandi, Sangareddy 502285, \\ India \\ e-mail: anandm@iith.ac.in
}

MS received 27 March 2016; revised 28 June 2016; accepted 9 August 2016

\begin{abstract}
A mechanistic model including the role of platelets is proposed for clot formation and growth in plasma in vitro. Initiation of clot formation is by the addition of tissue factor, and initiation via the intrinsic pathway is neglected. Activation of zymogens follows the extrinsic pathway cascade and reactions on platelet membranes are included. Platelet activation occurs due to thrombin and also due to other activated platelets. Inhibition of the active clotting factors is by ATIII and TFPI, whereas inhibition due to APC is not relevant in the conditions modeled. The model predictions matched existing data for thrombin production in synthetic plasma. The model predicts that inhibition of platelet-driven activation of platelets has a major effect on concentration of activated platelets in PRP, normal plasma and PPP. Inhibition of platelet activation by (other activated) platelets significantly delays thrombin production in PRP and normal plasma as compared to that by thrombin. Further, sensitivity analysis shows that the model is most sensitive to the activation of platelet membrane-bound factor $\mathrm{X}$ by the intrinsic tenase complex.
\end{abstract}

Keywords. Coagulation; platelets; concentration; inhibition; in vitro.

\section{Introduction}

Blood coagulation is vital for maintaining the integrity of the human circulation system. As an immediate response to blood vessel injury, vessel constriction and platelet plug formation occur leading to clot formation through coagulation. This provides longevity to the sealing of the injury thus, allowing it to heal.

The application of computational modeling to understand the individual reaction mechanisms, pathways and regulation of various sections of the coagulation cascade can contribute to development of safe and effective hemostatic agents and antithrombotic drugs [1, 2]. Mann [3] advocates the use of models to test hypothesis prior to experimental verification, and experimental verification itself precedes human trials. Several clot-based assays like prothrombin time (PT), activated partial thromboplastin time (aPTT), etc. used for coagulation testing [4] help identify bleeding abnormalities and monitor anticoagulant therapy [5]. Mechanistic models can aid such assays in determining the progress of coagulation in case of any clotting anomalies. Also, in addition to basic monitoring, such models can predict the sensitivity of specific mechanisms to various anticoagulant and antithrombotic drugs [6].

*For correspondence
An appropriate model depicting the coagulation cascade would include all aspects of the coagulation pathway including platelet activation and binding apart from the reaction kinetics. The role of platelets in coagulation is a key aspect which is not well understood in the current literature. Activated platelets play a significant role in thrombin production during coagulation [7]. Understanding the binding of pro-coagulant complexes to platelet surfaces and their activation under physiological conditions is necessary [8]. The coagulation model of Kuharsky and Fogelson [8] is one of the few to include platelets, but they have not studied the effect of higher than normal platelet concentration or of inhibition of platelet activation. Further, the rate constants used were those available at that time, and need to be updated with latest biochemical data, and this holds true for the rate constants in Fogelson et al [9] as well. There is a need, therefore, to develop a model that incorporates the role of platelets in the extrinsic pathway of blood coagulation in a form that can supplement an experimental assay. In this work, we have done this by including a separate (pseudo-homogeneous) variable for platelet concentration, and allowing for binding of coagulation factors (VIIIa, VIII, IXa, IX, Va, V, Xa, X, IIa, II) to activated platelets. Further, we allow for simultaneously different concentrations of procoagulant complexes by incorporating the binding-site density information from the model in Kuharsky and Fogelson [8]. The proposed model highlights the role of platelets and platelet-binding in blood coagulation in vitro. 
We formulate the problem in the following section and briefly survey the literature on models for clotting under static conditions. We then, highlight the salient features of our model along with the criteria considered for governing in vitro clot formation and progress in section 3; the details pertaining to the kinetic mechanisms involved in the model equations are given in Appendix 1. Section 4 presents the validation of the model with experimental data. This is followed by the model predictions for thrombin production in platelet-rich, normal and platelet-poor plasma, along with predictions for activated platelet concentration when platelet activation is inhibited by thrombin and by (other activated) platelets. Making such predictions is completely in tune with the approach of model-based hypothesis testing advocated by Mann [3]. Section 5 deals with a sensitivity analysis of the model. Finally, we summarize and discuss the results in section 6, and this includes a subsection on the limitations of and extensions to the model.

\section{Problem formulation}

We evaluate the role of platelet concentration and inhibition of platelet activation by simulating clot formation in vitro in a well-mixed, quiescent pool of plasma. Our model includes equations from the models of Hockin et al [10], Kuharsky and Fogelson [8] and Anand et al [11]. Our view of the extrinsic pathway of coagulation-as it occurs in vivo, and which we incorporate in the model equationsis based on the summary in Furie and Furie [12], and we give this below.

Damage of vascular tissue in the human body exposes blood to sub-endothelial collagen and microfibrils along with the tissue factor encrypted on the vessel walls; platelets adhere to the sub-endothelial collagen and microfibrils. Platelet activation follows, thus, enhancing platelet aggregation and leading to the formation of a platelet plug. This platelet plug initiates the closure of the wound, and is accompanied by formation of a longer-lasting blood clot. Formation of the blood clot primarily involves the conversion of the soluble plasma protein fibrinogen into insoluble fibrin by the action of thrombin. Thrombin is formed by the conversion of prothrombin as the end-result of the cascading activation of a series of plasma serine proteases (coagulation factors) that exist in a proenzyme form. Active factor VII formed in the extrinsic pathway by the action of tissue factor can bypass the early stages in intrinsic pathway by directly activating factor X. Also, thrombin exerts positive feedback effects by activating factors V, VIII and XI: Factors V and VIII act as co-factors in the formation of thrombin and factor $\mathrm{Xa}$, respectively. Both intrinsic and extrinsic pathways play complementary roles in in vivo hemostasis [13]. However, Furie and Furie [12] clearly state that the intrinsic pathway is not involved in in vivo coagulation.
Platelets play an essential role in the coagulation cascade. Activated platelets provide sites for the assembly of pro-coagulant complexes in the form of anionic phospholipids [14], and hence, localize thrombin production. Also, platelets regulate coagulation by protecting the bound enzymes from inactivation/inhibition [7]. Apart from the anionic membrane sites, activated platelets also supply coagulation factors like factors $\mathrm{V}$ and XI [15, 16]. Prothrombin activation on activated platelets enhances procoagulant activity [17].

Various naturally occurring anticoagulants balance the natural tendency for blood to clot in vivo. The most significant of these is antithrombin III (ATIII) which inhibits the activity of factors VIIa, IXa, Xa, XIa, XIIa in addition to thrombin (IIa). Yet another stoichiometric inhibitor of blood coagulation is tissue factor pathway inhibitor (TFPI). TFPI specifically acts on factor Xa and the TF-VIIa complex. van't Veer and Mann [18] have shown that presence of ATIII and TFPI controls thrombin production with respect to a threshold concentration of initiating factor TF-VIIa. Panteleev et al [19] developed an integrated model highlighting the common mechanism of inhibition of extrinsic tenase activity by XaTFPI complex. Activated protein C (APC) inactivates factors $\mathrm{Va}$ and VIIIa present in their respective complexes, prothrombinase and tenase [20]. We are only considering clotting in vitro; since thrombin needs to bind to its cofactor (thrombomodulin) on the endothelial surface for activation of PC [21], we ignore these reactions in our model.

In summary, the extrinsic coagulation pathway consists of complex interactions between the endothelium, sub-endothelium, platelets, coagulation factors and inhibitors. An overview of the reactions involved in the extrinsic pathway of coagulation in vitro that we have considered for our model is given in figure 1 .

\subsection{Literature survey}

Mathematical models of coagulation are classified as homogeneous, pseudo-homogeneous, or heterogeneous based on their treatment of platelets [22]. While in homogeneous models, concentrations are defined with respect to volume of a single phase (plasma), in heterogeneous models, species concentrations and kinetics are defined in multiple phases, i.e., in plasma (liquid-phase) and on platelets (surface-phase). Pseudo-homogeneous models ignore the fluid-particle nature of blood, and treat the heterogeneous system as homogeneous by defining platelet concentration based on plasma (or blood) volume. The models in Anand et al [11], Chatterjee et al [23] and Kuharsky and Fogelson [8] are examples of homogeneous, pseudo-homogeneous, and heterogeneous models, respectively.

Jones and Mann [24] have developed a homogeneous mathematical model for the extrinsic pathway leading to the generation of thrombin. They used a combination of empirical, estimated, and deduced rate constants for the 


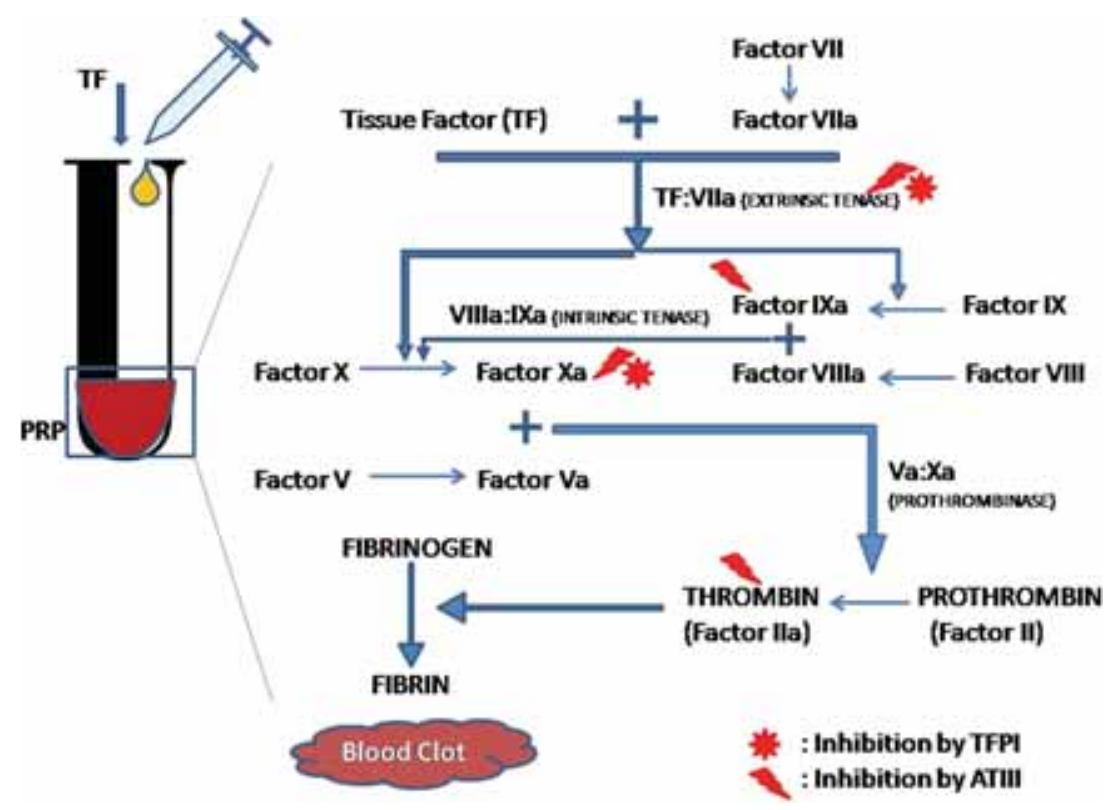

Figure 1. Overview of the extrinsic-pathway reactions used to develop the model.

activation reactions for factors IX, X, V and VIII, formation of thrombin, as well as the reactions for the assembly of the coagulation enzyme complexes (factors VIIIa-IXa: intrinsic tenase and factor $\mathrm{Va}-\mathrm{Xa}$ : prothrombinase) on phospholipid membrane. Their model system provides a reasonable approximation of empirical data. The model developed by Jones and Mann [24] was extended further by Hockin et al [10] to understand the stoichiometric interaction of the vitamin K-dependent pro-coagulant complexes and anticoagulants involved in hemostasis. The extended (homogeneous) mathematical model consists of 34 differential equations with 42 rate constants. The model incorporates the stoichiometric inhibitors TFPI and ATIII and, hence, better approximates the reaction pathway of thrombin formation/inhibition observed empirically. However, this model does not provide for regulation of prothrombinase via the decay of factor Va. The different models describing the dynamic progression of the coagulation cascade, and developed by Mann and co-workers, have been reviewed by Mann et al [25].

Kuharsky and Fogelson [8] have developed a heterogeneous model for coagulation of blood in the presence of flow, which takes into account both plasma-phase and surface-bound enzymes and zymogens, coagulation inhibitors, and activated and unactivated platelets. A key finding of this model is that the activity of the TF-VIIa complex is blocked by platelets covering the sub-endothelium. Platelet adhesion and aggregation following vessel injury is a non-local process. While continuum model approaches for thrombus formation [26] are available; however, since platelets are described as suspended in blood, a discretized simulation of thrombus formation and growth, on a platelet-by-platelet basis has also been performed [27].

Anand et al [11] presented a homogeneous model consisting of a set of 23 reaction-diffusion equations and a set of criteria, to simulate thrombus formation, growth, and thrombolysis in a quiescent pool of plasma exposed to a thrombogenic surface. A novel feature of this model was that it included equations for fibrinolysis (clot lysis). The model however, does not contain separate equations for platelet activation and aggregation, and instead assumes that activated platelets are available in sufficient numbers to sustain coagulation. An inclusion of platelets as a separate entity, along with reactions for binding to platelets, as well as separate equations for factors VII and VIIa (plasma and TF-bound) are the features which make the present model distinct from [11].

Clot growth-both in vivo and in vitro-has spatiotemporal characteristics; these have been studied earlier by analysing thrombin production and fibrin polymerization experimentally [28], and backed up theoretically [29]. In the most recent studies on clots, Moiseyev et al [30] have described the polymerization processes taking place in the common pathway stage of the coagulation cascade through a theoretical model. Their model can quantitatively predict the effects of key variables, e.g., thrombin concentration, plasmin concentration and shear rate on the mechanical properties of the fibrin clot. One of the drawbacks of this model is that it presumes that platelets have already been activated.

The role of blood-borne tissue factor remains an area of intense investigation. It has been shown that in the presence of persistent flow, a momentary expression of $\mathrm{TF}$ at specific 
sites can still sustain a pro-coagulant response independent of the initial TF stimulus. This is believed to be due to the onset of propagation phase wherein the thrombin activating potential is retained for sufficient time [31]. Experiments using factor V-, VII- and VIII-deficient plasma and computer simulations demonstrated that different responses to varied TF distributions are caused by two positive feedback loops in the blood coagulation network: activation of the TF-VII complex by factor Xa, and activation of factor $\mathrm{V}$ by thrombin [32]. This finding suggests a supply sensitivity to local TF density during blood coagulation making it necessary for TF to be modeled using a separate equation in a mathematical model.

\section{Model}

The salient features of the model are:

- A set of 34 reaction equations that governs the generation and depletion of tissue factor (TF), platelets (PL/AP), plasma-phase (IXa/IX,Xa/X,IIa/II,VIIIa/ $\mathrm{VIII}, \mathrm{Va} / \mathrm{V}, \mathrm{VII} / \mathrm{VIIa}$ ) and membrane-bound enzymes and zymogens $\left(\mathrm{IXa}^{m} / \mathrm{IX}^{m}, \quad \mathrm{Xa}^{m} / \mathrm{X}^{m}, \quad \mathrm{IIa}^{m} / \mathrm{II}^{m}\right.$, $\left.\mathrm{VIIIa}^{m} / \mathrm{VIII}^{m}, \mathrm{Va}^{m} / \mathrm{V}^{m}\right)$, surface bound enzyme complexes $\left(\mathrm{VIIIa}^{m}: \mathrm{IXa}^{m}, \mathrm{Va}^{m}: \mathrm{Xa}^{m}\right.$, TF:VII and TF:VIIa), inhibitors (ATIII, TFPI and Xa:TFPI) and fibrin/fibrinogen (Ia/I).

- Platelets are modeled as a soluble phase (not as a discrete particle phase) and variable concentrations of binding sites are incorporated. This makes the proposed model pseudo-homogeneous as mechanistic models go. A $0.01 \%$ initial level of activation is assumed for platelets.

- Initial concentrations of the reactants are those in human plasma. A $0.01 \%$ initial level of activation is assumed for enzymes in plasma. Initial concentrations of membrane bound zymogens/enzymes are set to zero.

Clotting is considered to occur in a test tube containing a well-mixed pool of platelet-rich plasma into which TF is added. In a simple compartmental system, the well-mixed assumption implies that while volume and concentration of a solute may vary with time, the solution in the system remains homogeneously mixed [33]. In our case, this simply means that we have a spatially uniform concentration of clotting factors in the test tube. We can therefore assume that reaction rates far exceed diffusion rates, and hence, neglect diffusion of zymogens and enzymes. Since we consider quiescent conditions, transport due to flow is neglected.

Platelet activation in the pool of plasma is assumed to be due to both thrombin as well as other activated platelets. Activation of zymogens and enzymatic reactions on platelet membranes proceed via the extrinsic pathway. Inhibition of the active clotting factors is by TFPI and ATIII. The intrinsic pathway is known to be activated upon contact of blood with any negatively-charged artificial surface. We neglect the intrinsic pathway by assuming that it is suppressed by addition of corn-trypsin inhibitor [34].

The schemes of the various reactions involved in the process of platelet and zymogen activation, inhibition and clot lysis have been outlined in table $1(\mathrm{a}-\mathrm{c})$. Reaction mechanisms have been obtained from the models developed by Kuharsky and Fogelson [8], Hockin et al [10] and Anand et al [11]. Table 1(a) outlines the reactions and rate constants involving platelet activation and aggregation and these are taken from Kuharsky and Fogelson [8]. Table 1(b) gives the scheme of reactions and their respective rate constants in plasma, whereas table 1 (c) details the reactions on platelet membranes. The reactions listed in table 1(a and c) are additions to the reactions in Anand et al [11].

The kinetic constants for each reaction are taken from the corresponding sources, unless otherwise mentioned: the constants for plasma-phase reactions are taken from Hockin et al [10] and Anand et al [11] (or from the original references mentioned therein) and the constants for platelet-activation and for binding to platelet membrane are taken from Kuharsky and Fogelson [8]. All the rate constants used are for human plasma at physiological conditions $\left(37^{\circ} \mathrm{C}, \mathrm{pH}=7.2\right.$ $\left.7.4,\left[\mathrm{Ca}^{2+}\right]=2.1-2.8 \mathrm{mM}\right)$ and they are numbered.

The initial concentrations of the zymogens, inhibitors and platelets (table 2) have been obtained from literature. They have been used previously in Hockin et al [10] and Anand et al [11].

Thirty four equations governing the generation/depletion of the various constituents are all of the form:

$$
\frac{d\left[Y_{i}\right]}{d t}=G_{i}, \quad i=1,2, \ldots, 34 .
$$

The notation $\left[Y_{i}\right]$ represents the concentration of the constituent $Y_{i}$. The time derivative of $\left[Y_{i}\right]$ is denoted by $\frac{d\left[Y_{i}\right]}{d t}$; $G_{i}$ represents the net rate of production of $Y_{i}$ as a result of enzymatic reactions (equal to the rate of production minus the rate of depletion).

The equations governing the generation and depletion of 34 species (including platelets) during blood coagulation are discussed in detail in Appendix 1. A sample equation is discussed below.

$$
\begin{aligned}
G_{\mathrm{Va}^{m}}= & k_{5}^{+}\left[\mathrm{AP}_{5}\right][\mathrm{Va}]+\frac{k_{5}\left[\mathrm{IIa}^{m}\right]\left[\mathrm{V}^{m}\right]}{K_{5 M}+\left[\mathrm{V}^{m}\right]}+\frac{k_{5 t}\left[\mathrm{Xa}^{m}\right]\left[\mathrm{V}^{m}\right]}{K_{5 t M}+\left[\mathrm{V}^{m}\right]} \\
& +k_{\mathrm{PRO}}^{-}\left[\mathrm{Va}^{m}: \mathrm{Xa}^{m}\right]-k_{\mathrm{PRO}}^{+}\left[\mathrm{Va}^{m}\right]\left[\mathrm{Xa}^{m}\right],-k_{5}^{-}\left[\mathrm{Va}^{m}\right] .
\end{aligned}
$$

The above expression gives the net rate of generation of membrane-bound clotting factor $\mathrm{Va}$ (i.e., $\mathrm{Va}^{m}$ ). The first and last terms in this expression represent the binding to, and dissociation from, platelets of plasma-phase Va. The second and third terms represent the activation of membrane-bound zymogen $\left(\mathrm{V}^{m}\right)$ by membrane-bound factors $\mathrm{IIa}^{m}$ and $\mathrm{Xa}^{m}$, respectively. The fourth and fifth terms 
Table 1. Reactions and kinetic constants.

\begin{tabular}{|c|c|c|c|}
\hline Reaction & (Number) Kinetic constant & Description & Reference \\
\hline \multicolumn{4}{|l|}{ (a) For reactions involving platelets } \\
\hline $\mathrm{PL}+\mathrm{AP} \stackrel{k p p}{\longrightarrow} 2 \mathrm{AP}$ & (54) $k p p=0.3 \mathrm{nM}^{-1} \mathrm{~s}^{-1}$ & $\begin{array}{c}\text { Platelet-activation of } \\
\text { platelet }\end{array}$ & [8] \\
\hline $\mathrm{PL}+\mathrm{IIa} \stackrel{k p 2}{\longrightarrow} A P$ & (55) $k p 2=0.37 \mathrm{~s}^{-1}$ & Platelet activation by IIa & [8] \\
\hline \multicolumn{4}{|l|}{ (b) For enzymatic reactions in plasma } \\
\hline $\mathrm{TF}+\mathrm{VII} \underset{k_{T 7}^{-}}{\stackrel{k_{T 7}^{+}}{\rightleftharpoons}} \mathrm{TF}: \mathrm{VII}$ & $\begin{array}{l}\text { (1) } k_{T 7}^{+}=3.2 \times 10^{-03} \mathrm{nM}^{-1} \mathrm{~s}^{-1} \\
\text { (2) } k_{T 7}^{-}=3.1 \times 10^{-03} \mathrm{~s}^{-1}\end{array}$ & $\begin{array}{l}\text { Binding of TF and VII } \\
\text { Dissociation of TF : VII }\end{array}$ & $\begin{array}{l}{[10]} \\
{[10]}\end{array}$ \\
\hline $\mathrm{TF}+\mathrm{VIIa} \underset{k_{\mathrm{T} 7 \mathrm{a}}}{\stackrel{k_{\mathrm{T} 7 \mathrm{a}}^{+}}{\rightleftharpoons}} \mathrm{TF}:$ VIIa & $\begin{array}{l}\text { (3) } k_{T 7 a}^{+}=0.023 \mathrm{nM}^{-1} \mathrm{~s}^{-1} \\
\text { (4) } k_{T 7 a}^{-}=3.1 \times 10^{-03} \mathrm{~s}^{-1}\end{array}$ & $\begin{array}{l}\text { Binding of TF and VIIa } \\
\text { Dissociation of TF : VIIa }\end{array}$ & $\begin{array}{l}{[10]} \\
{[10]}\end{array}$ \\
\hline $\mathrm{TF}: \mathrm{VIIa}+\mathrm{VII} \stackrel{k_{T F 7}}{\longrightarrow} \mathrm{TF}: \mathrm{VIIa}+\mathrm{VIIa}$ & (5) $k_{T F 7}=4.4 \times 10^{-04} \mathrm{nM}^{-1} \mathrm{~s}^{-1}$ & Auto-activation of VII & [10] \\
\hline $\mathrm{VII}+\mathrm{Xa} \stackrel{k_{10,7}}{\longrightarrow} V I I a+\mathrm{Xa}$ & (6) $k_{10,7}=0.013 \mathrm{nM}^{-1} \mathrm{~s}^{-1}$ & Xa-activation of VII & {$[10]$} \\
\hline $\mathrm{VII}+\mathrm{IIa} \stackrel{k_{2,7}}{\longrightarrow}$ VIIa + IIa & (7) $k_{2,7}=2.3 \times 10^{-05} \mathrm{nM}^{-1} \mathrm{~s}^{-1}$ & IIa-activation of VII & {$[10]$} \\
\hline $\mathrm{TF}: \mathrm{VIIa}+\mathrm{ATIII} \stackrel{h_{7}^{A T}}{\longrightarrow} \mathrm{TF}: \mathrm{VIIa}_{i}+\mathrm{ATIII}$ & (25) $h_{7}^{A T}=4.5 \times 10^{-07} \mathrm{nM}^{-1} \mathrm{~s}^{-1}$ & $\begin{array}{c}\text { ATIII inactivation of TF } \\
\text { : VIIa }\end{array}$ & {$[35]$} \\
\hline $\mathrm{TF}: \mathrm{VIIa}+\mathrm{Xa}: \mathrm{TFPI} \stackrel{h_{7}^{\mathrm{TP}}}{\longrightarrow} \mathrm{TF}: \mathrm{VIIa}_{i}+\mathrm{Xa}: \mathrm{TFPI}$ & (21) $h_{7}^{T P}=0.05 \mathrm{nM}^{-1} \mathrm{~s}^{-1}$ & $\begin{array}{c}\text { Xa : TFPI inactivation of } \\
\text { TF : VIIa }\end{array}$ & {$[10]$} \\
\hline $\mathrm{TF}: \mathrm{VIIa}+\mathrm{IX} \stackrel{k_{9}, K_{9 M}}{\longrightarrow} \mathrm{TF}: \mathrm{VIIa}+\mathrm{IXa}$ & (10) $k_{9}=0.26 \mathrm{~s}^{-1}$ & $\begin{array}{c}\text { TF : VIIa activation of } \\
\text { IX }\end{array}$ & {$[36]$} \\
\hline & (11) $K_{9 M}=243.0 \mathrm{nM}$ & $\begin{array}{c}\text { TF : VIIa activation of } \\
\text { IX }\end{array}$ & {$[36]$} \\
\hline $\mathrm{IXa}+\mathrm{ATIII} \stackrel{h_{9}}{\longrightarrow} \mathrm{IXi}+\mathrm{ATIII}$ & (23) $h_{9}=2.223 \times 10^{-04} \mathrm{nM}^{-1} \mathrm{~s}^{-1}$ & ATIII inactivation of IXa & {$[37]$} \\
\hline $\mathrm{TF}: \mathrm{VIIa}+\mathrm{X} \stackrel{k_{7,10}, K_{7,10 M}}{\longrightarrow}$ & (8) $k_{7,10}=1.15 \mathrm{~s}^{-1}$ & TF : VIIa activation of $X$ & {$[36]$} \\
\hline $\mathrm{TF}: \mathrm{VIIa}+\mathrm{Xa}$ & (9) $K_{7,10 \mathrm{M}}=450.0 \mathrm{nM}$ & TF : VIIa activation of $\mathrm{X}$ & [36] \\
\hline $\mathrm{Xa}+\mathrm{ATIII} \stackrel{h_{10}}{\longrightarrow} \mathrm{Xi}+\mathrm{ATIII}$ & (22) $h_{10}^{A T}=3.05 \times 10^{-06} \mathrm{nM}^{-1} \mathrm{~s}^{-1}$ & ATIII inactivation of Xa & {$[37]$} \\
\hline $\mathrm{Xa}+$ TFPI $\underset{h_{10}^{T P-}}{\stackrel{h_{10}^{T P+}}{\rightleftharpoons}}$ & (19) $h_{10}^{T P+}=4.381 \mathrm{nM}^{-1} \mathrm{~s}^{-1}$ & Binding of Xa with TFPI & $\begin{array}{l}\text { Estimated to fit } \\
\text { data in figure } 2\end{array}$ \\
\hline Xa : TFPI & $\begin{array}{c}(20) \\
h_{10}^{T P-}=5.293 \times 10^{-08} \mathrm{nM}^{-1} \mathrm{~s}^{-1}\end{array}$ & $\begin{array}{c}\text { Dissociation of Xa : } \\
\text { TFPI }\end{array}$ & $\begin{array}{l}\text { Estimated to fit } \\
\text { data in figure } 2\end{array}$ \\
\hline $\mathrm{II}+\mathrm{Xa} \stackrel{k_{2 t}}{\longrightarrow} I I a+\mathrm{Xa}$ & (12) $k_{2 t}=7.5 \times 10^{-06} \mathrm{nM}^{-1} \mathrm{~s}^{-1}$ & Xa-activation of II & {$[10]$} \\
\hline $\mathrm{IIa}+\mathrm{ATIII} \stackrel{h_{2}}{\longrightarrow} I I i+$ ATIII & (24) $h_{2}=1.79 \times 10^{-04} \mathrm{nM}^{-1} \mathrm{~s}^{-1}$ & ATIII inactivation of IIa & $\begin{array}{l}\text { Estimated to fit } \\
\text { data in figure } 2\end{array}$ \\
\hline $\mathrm{VIII}+\mathrm{IIa} \stackrel{k_{8}, K_{8 M}}{\longrightarrow} \mathrm{VIIIa}+\mathrm{IIa}$ & (13) $k_{8}=0.9 \mathrm{~s}^{-1}$ & IIa-activation of VIII & {$[8]$} \\
\hline & (14) $K_{8 M}=147.0 \mathrm{nM}$ & IIa-activation of VIII & {$[8]$} \\
\hline VIIIa $\stackrel{h_{8}}{\longrightarrow}$ VIII $i$ & (36) $h_{8}=0.0037 \mathrm{~s}^{-1}$ & $\begin{array}{c}\text { Spontaneous decay of } \\
\text { VIIIa }\end{array}$ & [11] \\
\hline $\mathrm{V}+\mathrm{IIa} \stackrel{k_{5}, K_{5 M}}{\longrightarrow} V a+\mathrm{IIa}$ & $\begin{array}{l}\text { (15) } k_{5}=0.233 \mathrm{~s}^{-1} \\
\text { (16) } K_{5 M}=71.7 \mathrm{nM}\end{array}$ & $\begin{array}{l}\text { IIa-activation of } \mathrm{V} \\
\text { IIa-activation of } \mathrm{V}\end{array}$ & $\begin{array}{l}{[8]} \\
{[8]}\end{array}$ \\
\hline $\mathrm{Va} \stackrel{h_{5}}{\longrightarrow} \mathrm{Vi}$ & (39) $h_{5}=0.0028 \mathrm{~s}^{-1}$ & Spontaneous decay of $\mathrm{Va}$ & {$[11]$} \\
\hline \multirow[t]{2}{*}{$\mathrm{I}+\mathrm{IIa} \stackrel{k_{f}, K_{f M}}{\longrightarrow} \mathrm{I} a$} & (17) $k_{f}=59.0 \mathrm{~s}^{-1}$ & $\begin{array}{l}\text { IIa-activation of } \\
\text { fibrinogen }\end{array}$ & {$[11]$} \\
\hline & (18) $K_{f M}=3160.0 \mathrm{nM}$ & $\begin{array}{l}\text { IIa-activation of } \\
\text { fibrinogen }\end{array}$ & {$[11]$} \\
\hline \multicolumn{4}{|l|}{ (c) For enzymatic reactions on membrane surface } \\
\hline $\mathrm{IX} / \mathrm{IXa}+\mathrm{AP}_{9} \underset{k_{9}^{-}}{\stackrel{k_{9}^{+}}{\rightleftharpoons}}$ & (48) $k_{9}^{+}=0.01 \mathrm{nM}^{-1} \mathrm{~s}^{-1}$ & $\begin{array}{l}\text { Platelet-binding of fIX/ } \\
\text { IXa }\end{array}$ & {$[8]$} \\
\hline $\mathrm{IX}^{m} / \mathrm{IXa}^{m}$ & (49) $k_{9}^{-}=0.0257 \mathrm{~s}^{-1}$ & $\begin{array}{l}\text { Dissociation of fIX/IXa } \\
\text { from platelets }\end{array}$ & {$[8]$} \\
\hline
\end{tabular}


Table 1 continued

\begin{tabular}{|c|c|c|c|}
\hline Reaction & (Number) Kinetic constant & Description & Reference \\
\hline $\mathrm{IXa}^{m}+\mathrm{VIIIa}^{m}$ & (26) $k_{T E N}^{+}=0.01 \mathrm{nM}^{-1} \mathrm{~s}^{-1}$ & $\begin{array}{c}\text { Binding of } \mathrm{IXa}^{m} \text { and } \\
\text { VIIIa }^{m}\end{array}$ & [10] \\
\hline$\underset{k_{T E N}^{-}}{\stackrel{k_{T E N}^{+}}{\rightleftharpoons}} \mathrm{VIIIa}^{m}: \mathrm{IXa}^{m}$ & (27) $k_{T E N}^{-}=5.0 \times 10^{-03} \mathrm{~s}^{-1}$ & $\begin{array}{l}\text { Dissociation of } \\
\mathrm{IXa}^{m}: \text { VIIIa }^{m}\end{array}$ & {$[10]$} \\
\hline $\mathrm{X} / \mathrm{Xa}+\mathrm{AP}_{10} \underset{k_{10}^{-}}{\stackrel{k_{10}^{+}}{\rightleftharpoons}}$ & (44) $k_{10}^{+}=0.029 \mathrm{nM}^{-1} \mathrm{~s}^{-1}$ & Platelet-binding of $\mathrm{fX} / \mathrm{Xa}$ & {$[38]$} \\
\hline $\mathrm{X}^{m} / \mathrm{Xa}^{m}$ & $(45) k_{10}^{-}=3.3 \mathrm{~s}^{-1}$ & $\begin{array}{l}\text { Dissociation of } \mathrm{fX} / \mathrm{Xa} \\
\text { from platelets }\end{array}$ & {$[38]$} \\
\hline $\mathrm{X}^{m}+\mathrm{VIIIa}^{m}: \mathrm{IXa}^{m}$ & (28) $k_{10}=8.33 \mathrm{~s}^{-1}$ & $\begin{array}{c}\mathrm{IXa}^{m}: \mathrm{VIIIa}^{m} \text { activation } \\
\text { of } \mathrm{X}^{m}\end{array}$ & {$[36]$} \\
\hline$\stackrel{k_{10}, K_{10 M}}{\longrightarrow} X a^{m}+\mathrm{VIIIa}^{m}: \mathrm{IXa}^{m}$ & (29) $K_{10 M}=63.0 \mathrm{nM}$ & $\begin{array}{c}\mathrm{IXa}^{m}: \mathrm{VIIIa}^{m} \text { activation } \\
\text { of } \mathrm{X}^{m}\end{array}$ & [36] \\
\hline$X a^{m}+V a^{m}$ & (30) $k_{\mathrm{PRO}}^{+}=0.4 \mathrm{nM}^{-1} \mathrm{~s}^{-1}$ & Binding of $\mathrm{Xa}^{m}$ and $\mathrm{Va}^{m}$ & {$[10]$} \\
\hline$\underset{k_{\mathrm{PRO}}^{-}}{\stackrel{k_{\mathrm{PRO}}^{+}}{+}} \mathrm{Va}^{m}: \mathrm{Xa}^{m}$ & (31) $k_{\mathrm{PRO}}^{-}=0.2 \mathrm{~s}^{-1}$ & Dissociation of $\mathrm{Xa}^{m} \mathrm{Va}^{m}$ & [10] \\
\hline $\mathrm{II} / \mathrm{IIa}+\mathrm{AP}_{2} \underset{\mathrm{k}_{2}^{-}}{\stackrel{\mathrm{k}_{2}^{+}}{\rightleftharpoons}}$ & (46) $k_{2}^{+}=0.01 \mathrm{nM}^{-1} \mathrm{~s}^{-1}$ & Platelet-binding of fII/IIa & [8] \\
\hline $\mathrm{II}^{m} / \mathrm{IIa}^{m}$ & (47) $k_{2}^{-}=5.9 \mathrm{~s}^{-1}$ & $\begin{array}{l}\text { Dissociation of fII/IIa } \\
\text { from platelets }\end{array}$ & [8] \\
\hline $\mathrm{II}^{m}+\mathrm{Xa}^{m}: \mathrm{Va}^{m}$ & (32) $k_{2}=22.4 \mathrm{~s}^{-1}$ & $\begin{array}{c}\mathrm{Xa}^{m}: \mathrm{Va}^{m} \text { activation of } \\
\mathrm{II}^{m}\end{array}$ & [11] \\
\hline$\stackrel{k_{2}, K_{2 M}}{\longrightarrow} I I a^{m}+\mathrm{Xa}^{m}: \mathrm{Va}^{m}$ & (33) $K_{2 M}=1060.0 \mathrm{nM}$ & $\begin{array}{c}\mathrm{Xa}^{m}: \mathrm{Va}^{m} \text { activation of } \\
\mathrm{II}^{m}\end{array}$ & [11] \\
\hline $\mathrm{VIII} / \mathrm{VIIIa}+\mathrm{AP}_{8} \underset{k_{8}^{-}}{\stackrel{k_{8}^{+}}{\rightleftharpoons}}$ & (50) $k_{8}^{+}=4.3 \times 10^{-03} \mathrm{nM}^{-1} \mathrm{~s}^{-1}$ & $\begin{array}{c}\text { Platelet-binding of fVIII/ } \\
\text { VIIIa }\end{array}$ & [39] \\
\hline $\mathrm{VIII}^{m} / \mathrm{VIIIa}^{m}$ & $(51) k_{8}^{-}=2.46 \times 10^{-03} \mathrm{~s}^{-1}$ & $\begin{array}{l}\text { Dissociation of fVIII/ } \\
\text { VIIIa from platelets }\end{array}$ & [39] \\
\hline $\mathrm{VIIII}^{m}+\mathrm{IIa}^{m} \stackrel{k_{8}^{m}, K_{8 M}^{m}}{\longrightarrow}$ & (40) $k_{8}^{m}=0.9 \mathrm{~s}^{-1}$ & $\mathrm{IIa}^{m}$-activation of $\mathrm{VIII}^{m}$ & [8] \\
\hline $\mathrm{VIIIa}^{m}+\mathrm{IIa}^{m}$ & (41) $K_{8 M}^{m}=200 \mathrm{nM}$ & $\mathrm{IIa}^{m}$-activation of $\mathrm{VIII}^{m}$ & [8] \\
\hline $\mathrm{VIII}^{m}+\mathrm{Xa}^{m} \stackrel{k_{8 t}^{m}, K_{8 t M}^{m}}{\longrightarrow}$ & (34) $k_{8 t}^{m}=0.023 \mathrm{~s}^{-1}$ & $\mathrm{Xa}^{m}$-activation of $\mathrm{VIII}^{m}$ & [8] \\
\hline $\mathrm{VIIII}^{m}+\mathrm{Xa}^{m}$ & (35) $K_{8 t M}^{m}=20.0 \mathrm{nM}$ & $\mathrm{Xa}^{m}$-activation of $\mathrm{VIII}^{m}$ & [8] \\
\hline $\mathrm{V} / \mathrm{Va}+\mathrm{AP}_{5} \underset{k_{5}^{-}}{\stackrel{k_{5}^{+}}{\rightleftharpoons}}$ & (52) $k_{5}^{+}=0.057 \mathrm{nM}^{-1} \mathrm{~s}^{-1}$ & Platelet-binding of $\mathrm{fV} / \mathrm{Va}$ & [8] \\
\hline $\mathrm{V}^{m} / \mathrm{Va}^{m}$ & $(53) k_{5}^{-}=0.17 \mathrm{~s}^{-1}$ & $\begin{array}{l}\text { Dissociation of } \mathrm{fV} / \mathrm{Va} \\
\text { from platelets }\end{array}$ & [8] \\
\hline $\mathrm{V}^{m}+\mathrm{IIa}^{m} \stackrel{k_{5}^{m}, K_{5 M}^{m}}{\longrightarrow}$ & (42) $k_{5}^{m}=0.23 \mathrm{~s}^{-1}$ & $\mathrm{IIa}^{m}$-activation of $\mathrm{V}^{m}$ & [8] \\
\hline $\mathrm{Va}^{m}+\mathrm{IIa}^{m}$ & (43) $K_{5 M}^{m}=71.7 \mathrm{nM}$ & $\mathrm{IIa}^{m}$-activation of $\mathrm{V}^{m}$ & [8] \\
\hline $\mathrm{V}^{m}+\mathrm{IIa}^{m} \stackrel{k_{5 t}^{m}, K_{5 t M}^{m}}{\longrightarrow}$ & (37) $k_{5 t}^{m}=0.046 \mathrm{~s}^{-1}$ & $\mathrm{Xa}^{m}$-activation of $\mathrm{V}^{m}$ & [8] \\
\hline $\mathrm{Va}^{m}+\mathrm{Xa}^{m}$ & (38) $K_{5 t M}^{m}=10.4 \mathrm{nM}$ & $\mathrm{Xa}^{m}$-activation of $\mathrm{V}^{m}$ & [8] \\
\hline
\end{tabular}

indicate the formation and dissociation of the prothrombinase $\left(\mathrm{Xa}^{m}: \mathrm{Va}^{m}\right)$ complex on the platelet membrane.

The following expression is used to calculate the concentration of binding sites per activated platelet for each clotting factor:

$$
[\mathrm{AP}]_{j}=N_{j} *[\mathrm{AP}]
$$

where $N_{j}$ is number of binding sites per platelet for clotting factor $j$ (table 3), and [AP] is concentration of activated platelets.

\section{Results}

We study the effect of platelet concentration on peak thrombin concentration and duration of quantitative thrombin production. We also study the effect of inhibition of platelet activation (by either thrombin or by other platelets) on thrombin and platelet concentrations. This will provide a better understanding of the significance of platelet-membrane surfaces during clotting. 
Table 2. Initial concentrations of proteins and platelets.

\begin{tabular}{|c|c|c|}
\hline Component & Normal conc. (nM) & Reference \\
\hline $\mathrm{TF}$ & Variable & \\
\hline VII & 10.0 & [10] \\
\hline $\mathrm{VII}^{m}$ & 0.0 & \\
\hline VIIa & 0.1 & {$[10]$} \\
\hline $\mathrm{VIIa}^{m}$ & 0.0 & \\
\hline $\mathrm{IXa}^{m}$ & 0.0 & \\
\hline $\mathrm{IX}^{m}$ & 0.0 & \\
\hline IXa & 0.009 & \\
\hline IX & 90.0 & [11] \\
\hline $\mathrm{Xa}^{m}$ & 0.0 & \\
\hline $\mathrm{X}^{m}$ & 0.0 & \\
\hline $\mathrm{Xa}$ & 0.017 & \\
\hline $\mathrm{X}$ & 170.0 & [11] \\
\hline $\mathrm{IIa}^{m}$ & 0.0 & \\
\hline $\mathrm{II}^{m}$ & 0.0 & \\
\hline IIa & 0.140 & \\
\hline II & 1400.0 & {$[11]$} \\
\hline PL & 10.0 & {$[40]$} \\
\hline AP & 0.001 & \\
\hline VIIIa $^{m}$ & 0.0 & \\
\hline $\mathrm{VIII}^{m}$ & 0.0 & \\
\hline VIIIa & 0.00007 & \\
\hline VIII & 0.7 & [11] \\
\hline $\mathrm{IXa}^{m}: \mathrm{VIIIa}^{m}$ & 0.0 & \\
\hline $\mathrm{Va}^{m}$ & 0.0 & \\
\hline $\mathrm{V}^{m}$ & 0.0 & \\
\hline $\mathrm{Va}$ & 0.002 & \\
\hline V & 20.0 & [11] \\
\hline $\mathrm{Xa}^{m}: \mathrm{Va}^{m}$ & 0.0 & \\
\hline I & 7000.0 & {$[11]$} \\
\hline Ia & 0.70 & \\
\hline TFPI & 2.5 & [11] \\
\hline Xa:TFPI & 0.0 & \\
\hline ATIII & 3400.0 & [11] \\
\hline
\end{tabular}

\subsection{Numerical scheme}

The set of 34 ODEs and initial conditions are non-dimensionalised according to the following procedure: $t^{*}=t / T, Y_{i}^{*}=Y_{i} / Y_{i}(t=0), G_{i}^{*}=G_{i} T / Y_{i}(t=0)$. They are then solved using the "ode15s" algorithm (meant for stiff ODEs) in MATLAB (version R2012a). The timemarching is performed using a variable (non-dimensional) time-step until relative tolerance of each variable at each time step is 0.001 or absolute tolerance is $10^{-6}$. The simulations are performed for $1800 \mathrm{~s}$ (i.e., $30 \mathrm{~min}$ ), and are reported on a uniform grid of spacing $1 \mathrm{~s}$. Mesh refinement was done by solving for time-steps of 5, 3 and $1 \mathrm{~s} .0 \%$ error was observed in the solution with progressive time-steps.
Table 3. Binding sites per platelet for individual clotting factors.

\begin{tabular}{lcc}
\hline Clotting factor & $N$ & Reference \\
\hline X & 2700 & {$[8]$} \\
II & 2000 & {$[8]$} \\
IX & 250 & {$[41]$} \\
IXa & 550 & {$[41]$} \\
V & 2700 & {$[8]$} \\
VIII & 750 & {$[42]$} \\
\hline
\end{tabular}

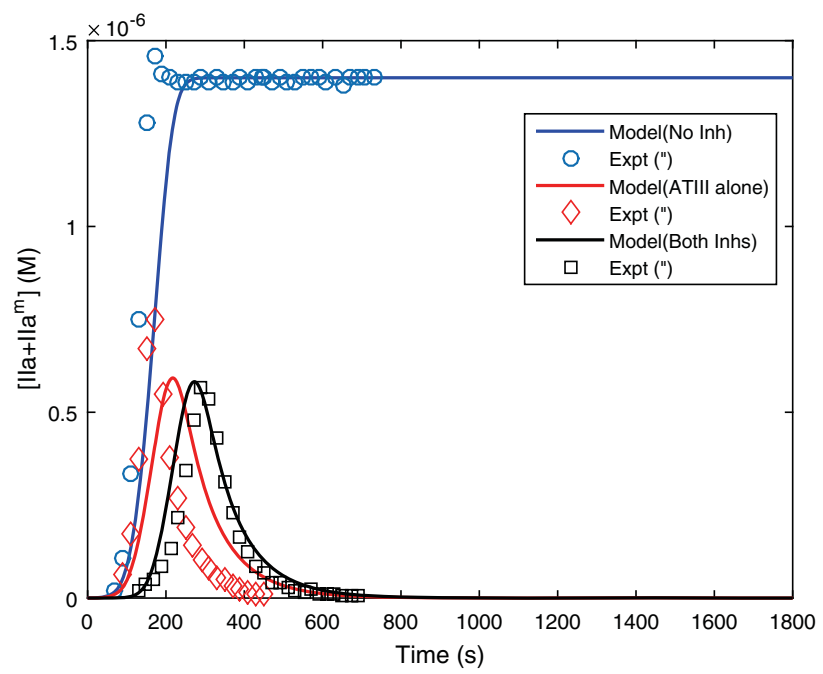

Figure 2. Total thrombin production at $[\mathrm{TF}]=25 \mathrm{pM}$ with respect to presence and absence of inhibitors (TFPI, ATIII).

\subsection{Model validation}

We compare the model predictions with the data for in vitro thrombin production obtained by Hockin et al [10]. Total thrombin (in plasma as well as on platelet membranes) generated for $[\mathrm{TF}]=25 \mathrm{pM}$ is high in the absence of both inhibitors (ATIII and TFPI) (figure 2, blue line). However, it decreases gradually in the presence of both inhibitors (figure 2, black line), and with ATIII alone (figure 2, red line). Model predictions are thus consistent with experimental data that ATIII is a stronger inhibitor of thrombin production than TFPI. We note here that in a biological system like blood with hundreds of biochemical processes, and not just the ones we have selected, small seemingly insignificant differences in experimental conditions produce large changes in the interaction between proteins and in their manifestation in the formation of a clot. It is therefore an impossible task to get point-to-point match between data from in vitro coagulation with all aspects of coagulation for any model of coagulation given the multiplicity of sources and the difficulty in keeping experimental conditions exactly the same in each blood sample. The discrepancy between predictions and data should be viewed in this regard. 


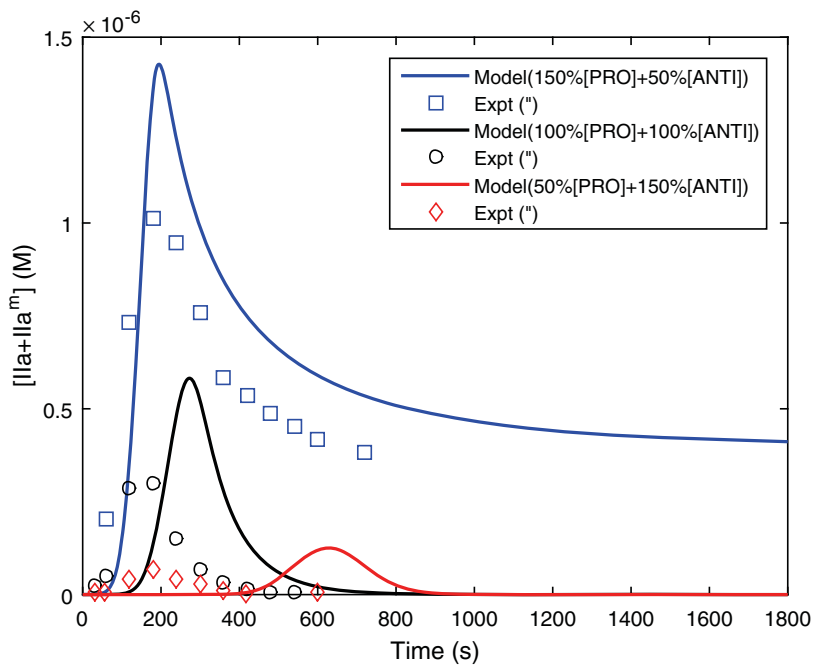

Figure 3. Total thrombin production at $[\mathrm{TF}]=5 \mathrm{pM}$ with different $[\mathrm{PRO}]+[\mathrm{ANTI}]$. Model compared with experimental data from Butenas et al [43].

Further, the qualitative trend of thrombin production predicted by the model matches the experimental data for in vitro thrombin production from Butenas et al [43], where different initial concentrations of procoagulant factors (II, V, VIII, IX, X) and anticoagulants (ATIII, TFPI) are taken together. An elevation in peak and duration of thrombin production is observed with $150 \%$ (procoagulants) $+50 \%$ (anticoagulants), while a decrease is seen with $50 \%$ (procoagulants) $+150 \%$ (anticoagulants) (figure 3 ).

\subsection{Model predictions}

4.3a Effect of platelet concentration: In humans, the normal platelet counts vary from $150,000 / \mu \mathrm{L}$ to $350,000 / \mu \mathrm{L}$, with the mean count being $250,000 / \mu \mathrm{L}$. Platelet-rich plasma (PRP) is defined as having a platelet concentration of $1,000,000 / \mu \mathrm{L}$ and above [44], while platelet-poor plasma (PPP) is plasma with a platelet count below $10,000 / \mu \mathrm{L}$ [45]. We take a concentration of $10 \mathrm{nM}$ to be the equivalent of normal platelet count in human plasma $\left(2.5 \times 10^{5} / \mu \mathrm{L}\right)$ by a procedure explained in Anand et al [40]. Consequently, we use a platelet concentration of 40 and $0.4 \mathrm{nM}$ for PRP and PPP, respectively. The consequence of varying initial platelet count (equivalently $[R P]_{0}$ ) on thrombin production is shown in figure 4. There is a significant rise in the peak thrombin concentration, increase in the duration of quantitative thrombin production, and evident alteration in the profile, in PRP compared to normal plasma. Conversely, the onset of peak thrombin production is significantly delayed for PPP, and this is also along expected lines.

The effect of inhibition of platelet-driven and thrombindriven platelet activation on platelet activation was studied for platelet-rich plasma (PRP), normal plasma and platelet-

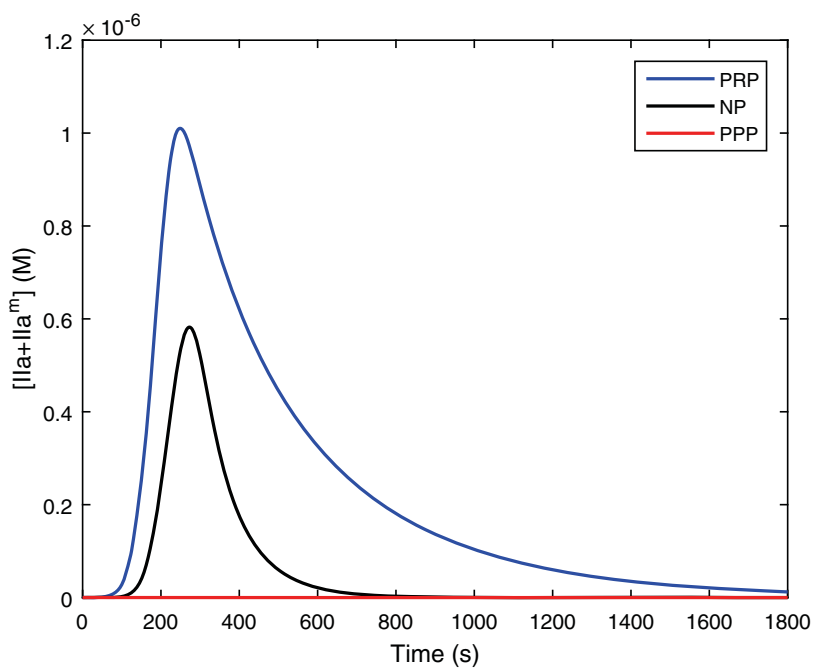

Figure 4. Effect of platelet concentration on thrombin production.

poor plasma (PPP): Figure 5(a), (b) and (c) respectively. The model predicts that platelet activation by (other) activated platelets is more significant in PRP, normal plasma and PPP also (figure 5). Further, the total thrombin produced when platelet activation by other platelets is inhibited, shows a significant delay in onset of quantitative production in PRP and normal plasma (figure $5 \mathrm{~d}$, e). However, the same inhibition shows no significant effect in PPP (results obtained but not shown).

These results suggest that platelet-driven activation of platelets plays a major role in activation of platelets and subsequently, in the onset of thrombin production. This may be rationalized by noting that the term in Eq. (19) in Appendix 1, governing platelet activation by thrombin reduces to $k p 2[\mathrm{PL}]$ for high concentrations of IIa. Thus, the term governing platelet activation by platelets $(k p p[\mathrm{PL}][\mathrm{AP}])$ dominates since $k p p$ and $k p 2$ are of the same order.

\section{Sensitivity analysis}

Sensitivity analysis calculates the effect of variations of parameters (rate constants) on the model predictions (reactant concentrations) and determines the rate constant to which the predictions are most/least sensitive. Each rate constant in the model is varied in a predesignated manner, and the resultant variation in each species' concentration is thus obtained. A short literature survey gives two procedures of sensitivity analysis for coagulation models: the one in Danforth et al [46], and the other in Luan et al [1]. While Danforth et al [46] give a sampling-based method using an ensemble standard deviation, Luan et al [1] provide a local variance decomposition method using the derivative of the output concentration with respect to the input parameters. For the present model, the sampling-based method is preferred since the range of perturbation used in it is the expected range 
(a) PRP

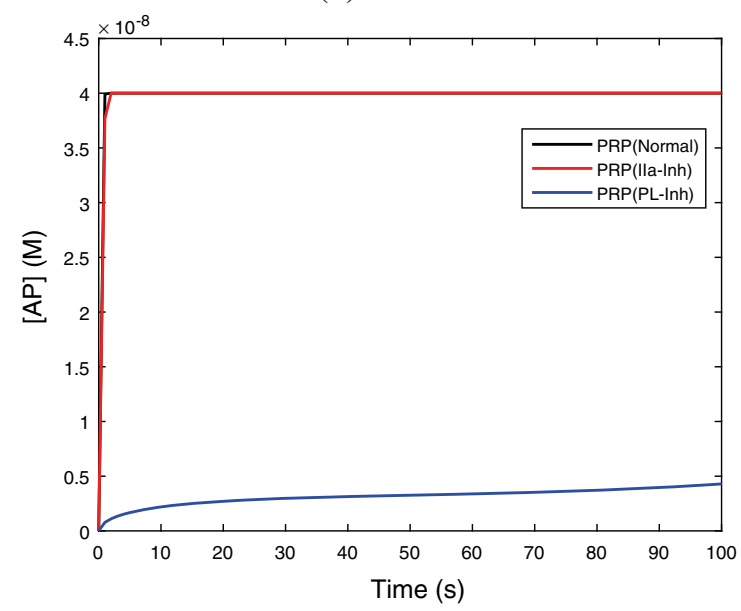

(b) Normal plasma

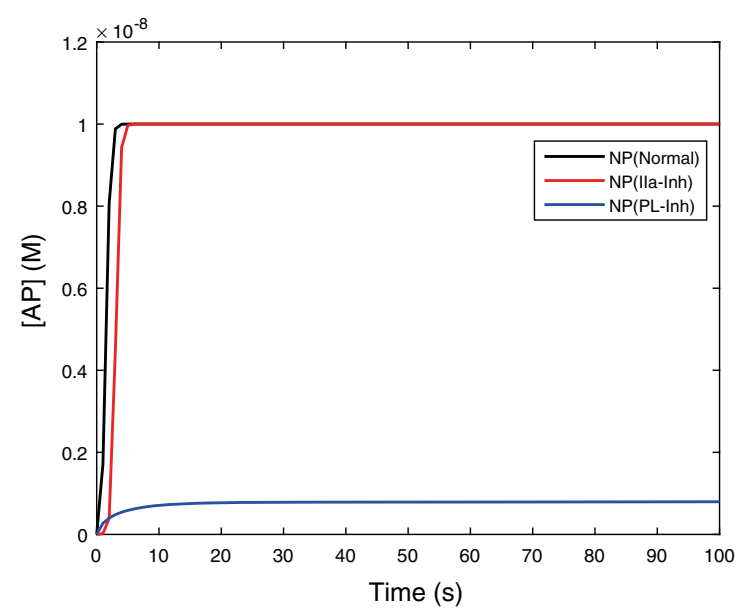

(c) PPP

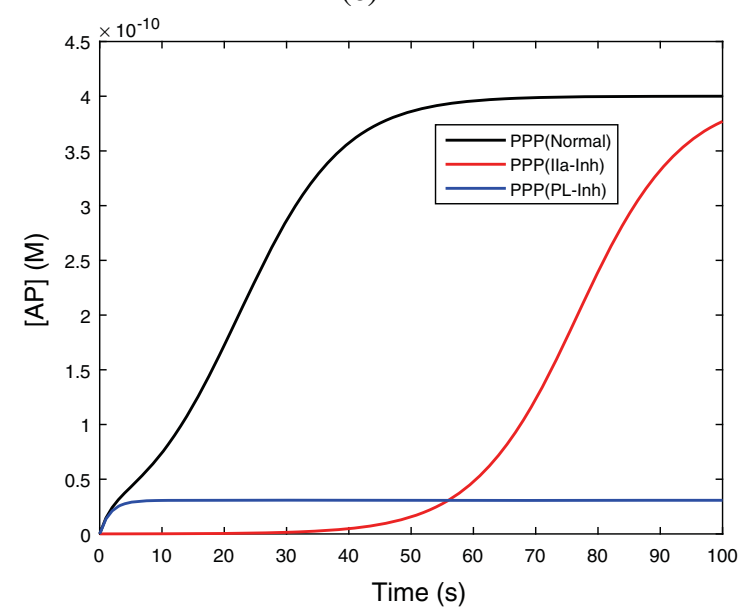

(d) PRP

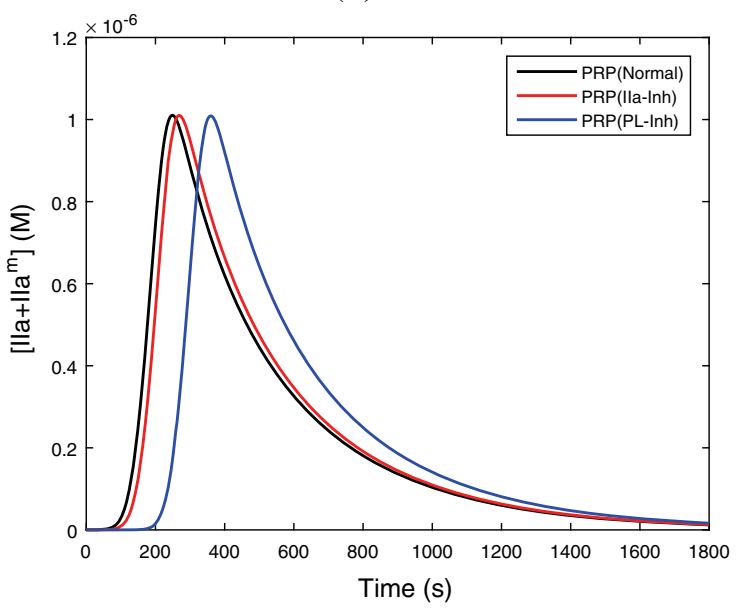

(e) Normal plasma

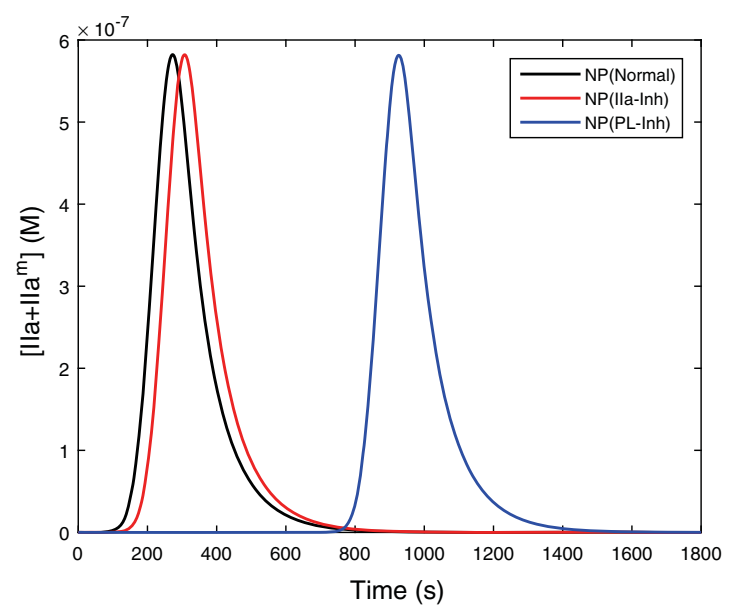

Figure 5. Activated-platelet production $(\mathbf{a}-\mathbf{c})$ and total thrombin production $(\mathbf{d}-\mathbf{e})$ with inhibition of platelet activation at $[\mathrm{TF}]=5 \mathrm{pM}$, in PRP, normal plasma and PPP.

of variability of experimentally measured rate constants. In addition, this procedure yields a more indicative statistic (see appendix in Naidu and Anand [47]). We list the constants to which the model prediction of all species' concentrations are most sensitive in the order of explained variance, $E_{v a r}^{m}$ (figure 6), which is calculated as follows: 


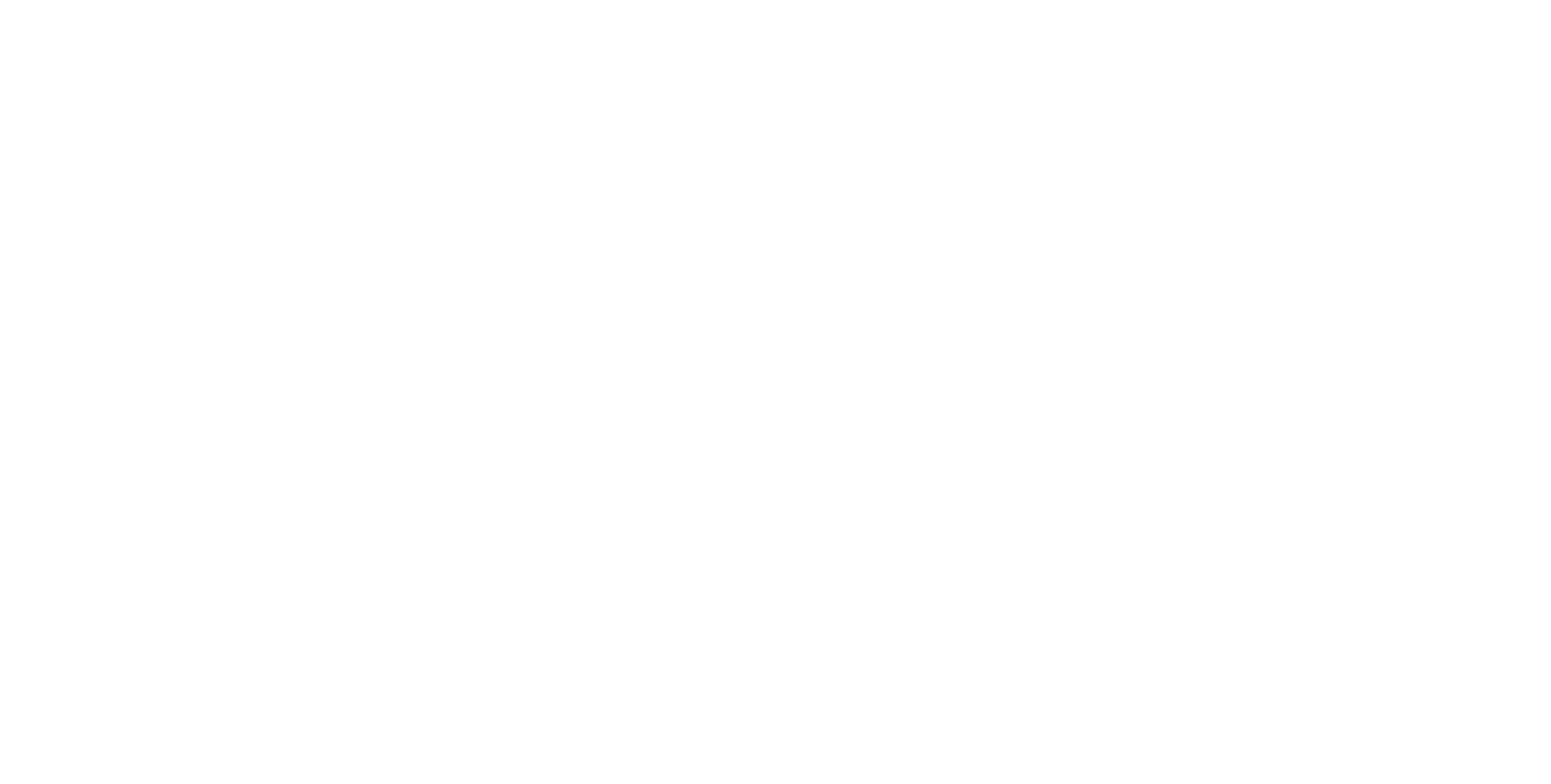

Figure 6. Decreasing order of cumulative explained variance $\left(E_{v a r}^{m}\right)$ versus model rate constant number.

Table 4. Sensitivity analysis.

\begin{tabular}{|c|c|c|}
\hline (Number) Kinetic constant & Reaction & Sensitivity \\
\hline (28) $k_{10}=39.85 \mathrm{~s}^{-1}$ & $\mathrm{X}^{m}+\mathrm{VIIIa}^{m}: \mathrm{IXa}^{m} \stackrel{k_{10}, K_{10 M}}{\longrightarrow} \mathrm{Xa}^{m}+\mathrm{VIIIa}^{m}: \mathrm{IXa}^{m}$ & Highest \\
\hline (5) $k_{T F 7}=4.4 \times 10^{-04} \mathrm{nM}^{-1} \mathrm{~s}^{-1}$ & $\mathrm{TF}: \mathrm{VIIa}+\mathrm{VII} \stackrel{k_{T F 7}}{\longrightarrow} \mathrm{TF}: \mathrm{VIIa}+\mathrm{VIIa}$ & Least \\
\hline
\end{tabular}

$$
E_{v a r}^{m}=\frac{\sum_{j=1}^{m} \Gamma_{k_{j}}}{\sum_{j=1}^{55} \Gamma_{k_{j}}} .
$$

We refer the readers to Naidu and Anand [47] for the details regarding above terms and calculations regarding explained variance. Decreasing order of explained variance shows that the rate constant, $k_{10}$ for the activation of platelet membrane-bound factor $\mathrm{X}$ by intrinsic tenase is responsible for the maximum changes in model predictions. The model is least sensitive to variations in the rate constant $k_{T F 7}$ for auto-activation of factor VII: see table 4.

\section{Summary and discussion}

We have developed a pseudo-homogeneous platelet-plasma model for clot formation and growth in vitro in quiescent plasma. Model parameters used are those for human plasma. Model is validated by comparing results with available experimental data for synthetic plasma. Effect of inhibitors on thrombin production matched with what was reported in experiments. The model is then used to evaluate the effect of platelet count (in PPP, normal plasma and PRP) on peak thrombin concentration as well as duration of thrombin production. Inhibition of platelet-driven plateletactivation is seen to produce the most significant decrease in platelet activation, as well as the highest delays in peak thrombin production. Finally, we performed a sensitivity analysis of the model to understand the robustness of the predictions to changes in each rate constant.

- The model predicts that ATIII is a more potent inhibitor of thrombin production than TFPI alone. This is consistent with our current understanding of coagulation. Also, a qualitative as well as quantitative match is obtained with experimental data for thrombin production using varying ratios of procoagulant and anticoagulant species.

- The model predicts that increase in platelet count will lead to increase in both peak thrombin concentration as well as duration of thrombin production.

- Inhibition of platelet-driven platelet activation has a more pronounced effect, compared to inhibition of 
thrombin-driven platelet activation, on concentration of activated platelets in PRP, normal plasma and PPP. However, inhibition of platelet-driven and thrombindriven platelet activations shows no significant effect on thrombin production in PPP, whereas these lead to a huge delay in quantitative thrombin production in both PRP and normal plasma.

- Sensitivity analysis of the model reveals that the model is most sensitive to the rate constant governing the activation of platelet membrane-bound factor $\mathrm{X}$ by intrinsic tenase, whereas it is least sensitive to the rate constant governing auto-activation of factor VII.

The strength of the proposed model lies in two aspects. First is its consistency with good mathematical practice as elaborated in Hemker and Ataullakhanov [48]: All rate constants were for human plasma, and fitting of only three rate constants out of 55 (listed in table 1(b)) was done using the fmincon algorithm in MATLAB. Second is its inclusion of platelets and binding-site density as a separate term, and using this to predict their effects on extrinsic coagulation in the manner advocated by Mann [3]. However, the model has some limitations. We discuss the limitations and the extensions that may address the same, in the following section.

\subsection{Limitations and extensions}

The current model incorporates the role of platelets in the extrinsic pathway of clot formation and growth in vitro. Though, the model incorporates platelets as a separate entity and also includes the reactions involving platelets, it does not account for platelet-activating constituents like adenosine di-phosphate (ADP), and von-Willebrand factor (vWF). Inhibitors of such platelet-activating constituents affect thrombus formation [49]. Hence, inclusion of such anti platelet agents in the model remains to be done: Such an exercise will be useful to understand their significance for therapeutic use.

Due to certain unaccountable results with respect to thrombin production, the kinetic constants for factor $\mathrm{Xa}$ binding to and dissociation from TFPI have been estimated along with that for ATIII inhibition of factor IIa. Further, since rate constants are taken from three different models, there is a possibility, however remote, that there may be variation in the conditions under which some constants were obtained. In our next study, we will investigate the incongruities arising in the model predictions due to use of rate constants from different sources in the literature and will highlight the need for careful selection of such rate constants.

To extend the conclusions to the in vivo case, the model predictions will have to be obtained in the presence of flow. One possible way of doing this is shown in Sequeira and Bodnar [50], where the model in Anand et al [11] is studied in the presence of flow.

\section{Acknowledgements}

MS was supported by the MHRD Fellowship for Research Scholars administered by IIT Hyderabad.

\section{Appendix 1: Model reactions}

$$
\begin{aligned}
& G_{\mathrm{TF}}=-k_{T 7}^{+}[\mathrm{TF}][\mathrm{VII}]+k_{T 7}^{-}[\mathrm{TF}: \mathrm{VII}] \\
& -k_{T 7 a}^{+}[\mathrm{TF}][\mathrm{VIIa}]+k_{T 7 a}^{-}[\mathrm{TF}: \mathrm{VIIa}] \text {. } \\
& G_{\mathrm{VII}}=-k_{T 7}^{+}[\mathrm{TF}][\mathrm{VII}]+k_{T 7}^{-}[\mathrm{TF}: \mathrm{VII}]-k_{T F 7}[\mathrm{TF}: \mathrm{VIIa}][\mathrm{VII}] \\
& -k_{10,7}[\mathrm{Xa}][\mathrm{VII}]-k_{2,7}[\mathrm{IIa}][\mathrm{VII}] \text {. } \\
& G_{\mathrm{TF}: \mathrm{VII}}=k_{T 7}^{+}[\mathrm{TF}][\mathrm{VII}]-k_{T 7}^{-}\left[\mathrm{VII}^{m}\right] . \\
& G_{\mathrm{VIIa}}=-k_{T 7 a}^{+}[\mathrm{TF}][\mathrm{VIIa}]+k_{T 7 a}^{-}[\mathrm{TF}: \mathrm{VIIa}] \\
& +k_{T F 7}[\mathrm{TF}: \mathrm{VIIa}][\mathrm{VII}] \\
& +k_{10,7}[\mathrm{Xa}][\mathrm{VII}]+k_{2,7}[\mathrm{IIa}][\mathrm{VII}] \text {. } \\
& G_{\mathrm{TF}: \mathrm{VIIa}}=k_{T 7 a}^{+}[\mathrm{TF}][\mathrm{VIIa}]-k_{T 7 a}^{-}[\mathrm{TF}: \mathrm{VIIa}] \\
& -h_{7}^{T P}[\mathrm{TFPI}: \mathrm{Xa}][\mathrm{TF}: \mathrm{VIIa}] \\
& -h_{7}^{A T}[\mathrm{ATIII}][\mathrm{TF}: \mathrm{VIIa}] \text {. } \\
& G_{\mathrm{IX}}=-\frac{k_{9}[\mathrm{TF}: \mathrm{VIIa}][\mathrm{IX}]}{K_{9 M}+[\mathrm{IX}]}-k_{9}^{+} N_{9}[\mathrm{AP}][\mathrm{IX}]+k_{9}^{-}\left[\mathrm{IX}^{m}\right] . \\
& G_{\mathrm{IXa}}=\frac{k_{9}[\mathrm{TF}: \mathrm{VIIa}][\mathrm{IX}]}{K_{9 M}+[\mathrm{IX}]}-k_{9}^{+} N_{9}[\mathrm{AP}][\mathrm{IXa}] \\
& +k_{9}^{-}\left[\mathrm{IXa}^{m}\right]-h_{9}[\mathrm{IXa}][\mathrm{ATIII}] \text {. } \\
& G_{\mathrm{IX}^{\mathrm{m}}}=k_{9}^{+} N_{9}[\mathrm{AP}][\mathrm{IX}]-k_{9}^{-}\left[\mathrm{IX}^{m}\right] . \\
& G_{\text {IXa }^{\mathrm{m}}}=-k_{\text {TEN }}^{+}\left[\mathrm{VIIIa}^{m}\right]\left[\mathrm{IXa}^{m}\right]+k_{T E N}^{-}\left[\mathrm{VIIIa}^{m}: \mathrm{IXa}^{m}\right] \\
& +k_{9}^{+} N_{9}[\mathrm{AP}][\mathrm{IXa}]-k_{9}^{-}\left[\mathrm{IXa}^{m}\right] \text {. } \\
& G_{\mathrm{X}}=-\frac{k_{7,10}[\mathrm{TF}: \mathrm{VIIa}][\mathrm{X}]}{K_{7,10 M}+[\mathrm{X}]}-k_{10}^{+} N_{10}[\mathrm{AP}][\mathrm{X}]+k_{10}^{-}\left[\mathrm{X}^{m}\right] \\
& G_{\mathrm{Xa}}=\frac{k_{7,10}[\mathrm{TF}: \mathrm{VIIa}][\mathrm{X}]}{K_{7,10 M}+[\mathrm{X}]}-h_{10}^{T P+}[\mathrm{TFPI}][\mathrm{Xa}] \\
& +h_{10}^{T P-}[\mathrm{Xa}: \mathrm{TFPI}] \\
& -h_{10}^{A T}[\mathrm{ATIII}][\mathrm{Xa}]-k_{10}^{+} N_{10}[\mathrm{AP}][\mathrm{Xa}]+k_{10}^{-}\left[\mathrm{Xa}^{\mathrm{m}}\right] \text {. } \\
& G_{\mathrm{X}^{m}}=-\frac{k_{10}\left[\mathrm{VIIIa}^{m}: \mathrm{IXa}^{m}\right]\left[\mathrm{X}^{m}\right]}{K_{10 M}+\left[\mathrm{X}^{m}\right]} \\
& +k_{10}^{+} N_{10}[\mathrm{AP}][\mathrm{X}]-k_{10}^{-}\left[\mathrm{X}^{m}\right] \text {. }
\end{aligned}
$$




$$
\begin{aligned}
G_{\mathrm{Xa}^{m}}= & \frac{k_{10}\left[\mathrm{VIIIa}^{m}: \mathrm{IXa}^{m}\right]\left[\mathrm{X}^{m}\right]}{K_{10 M}+\left[\mathrm{X}^{m}\right]}-k_{\mathrm{PRO}}^{+}\left[\mathrm{Va}^{m}\right]\left[\mathrm{Xa}^{m}\right] \\
+ & k_{\mathrm{PRO}}^{-}\left[\mathrm{Va}^{m}: \mathrm{Xa}^{m}\right]+k_{10}^{+} N_{10}[\mathrm{AP}][\mathrm{Xa}]-k_{10}^{-}\left[\mathrm{Xa}^{\mathrm{m}}\right] . \\
G_{\mathrm{II}}= & -k_{2 t}[\mathrm{Xa}][\mathrm{II}]-k_{2}^{+} N_{2}[\mathrm{AP}][\mathrm{II}]+k_{2}^{-}\left[\mathrm{II}^{m}\right] . \\
G_{\mathrm{IIa}}= & k_{2 t}[\mathrm{Xa}][\mathrm{II}]-k_{2}^{+} N_{2}[\mathrm{AP}][\mathrm{IIa}]+k_{2}^{-}\left[\mathrm{IIa}^{m}\right] \\
& -h_{2}[\mathrm{ATIII}][\mathrm{IIa}] . \\
G_{\mathrm{II}^{m}}= & -\frac{k_{2}\left[\mathrm{Va}^{m}: \mathrm{Xa}^{m}\right]\left[\mathrm{II}^{m}\right]}{K_{2 M}+\left[\mathrm{II}^{m}\right]}+k_{2}^{+} N_{2}[\mathrm{AP}][\mathrm{II}]-k_{2}^{-}\left[\mathrm{II}^{m}\right] .
\end{aligned}
$$$$
G_{\mathrm{IIa}^{m}}=\frac{k_{2}\left[\mathrm{Va}^{m}: \mathrm{Xa}^{m}\right]\left[\mathrm{II}^{m}\right]}{K_{2 M}+\left[\mathrm{II}^{m}\right]}+k_{2}^{+} N_{2}[\mathrm{AP}][\mathrm{IIa}]-k_{2}^{-}\left[\mathrm{IIa}^{m}\right] .
$$$$
G_{\mathrm{PL}}=-k p p[\mathrm{PL}][\mathrm{AP}]-\frac{k p 2[\mathrm{PL}][\mathrm{IIa}]}{1+[\mathrm{IIa}]} .
$$$$
G_{\mathrm{AP}}=k p p[\mathrm{PL}][\mathrm{AP}]+\frac{k p 2[\mathrm{PL}][\mathrm{IIa}]}{1+[\mathrm{IIa}]} .
$$$$
G_{\mathrm{VIII}}=-\frac{k_{8}[\mathrm{IIa}][\mathrm{VIII}]}{K_{8 M}+[\mathrm{VIII}]}-k_{8}^{+} N_{8}[\mathrm{AP}][\mathrm{VIII}]+k_{8}^{-}\left[\mathrm{VIII}^{m}\right] .
$$$$
G_{\mathrm{VIII}}=\frac{k_{8}[\mathrm{IIa}][\mathrm{VIII}]}{K_{8 M}+[\mathrm{VIII}]}-k_{8}^{+} N_{8}[\mathrm{AP}][\mathrm{VIIIa}]
$$$$
+k_{8}^{-}\left[\mathrm{VIIIa}^{m}\right]-h_{8}[\mathrm{VIIIa}] \text {. }
$$$$
G_{\mathrm{VIII}}{ }^{m}=-\frac{k_{8}^{m}\left[\mathrm{IIa}^{m}\right]\left[\mathrm{VIII}^{m}\right]}{K_{8 M}^{m}+\left[\mathrm{VIII}^{m}\right]}-\frac{k_{8 t}^{m}\left[\mathrm{Xa}^{m}\right]\left[\mathrm{VIII}^{m}\right]}{K_{8 t M}^{m}+\left[\mathrm{VIII}^{m}\right]}
$$$$
+k_{8}^{+} N_{8}[\mathrm{AP}][\mathrm{VIII}]-k_{8}^{-}\left[\mathrm{VIII}^{m}\right] \text {. }
$$$$
G_{\mathrm{VIII}^{m}}=\frac{k_{8}^{m}\left[\mathrm{IIa}^{m}\right]\left[\mathrm{VIII}^{m}\right]}{K_{8 M}^{m}+\left[\mathrm{VIII}^{m}\right]}+\frac{k_{8 t}^{m}\left[\mathrm{Xa}^{m}\right]\left[\mathrm{VIII}^{m}\right]}{K_{8 t M}^{m}+\left[\mathrm{VIII}^{m}\right]}
$$$$
+k_{8}^{+} N_{8}[\mathrm{AP}][\mathrm{VIIIa}]
$$$$
-k_{8}^{-}\left[\mathrm{VIIIa}^{m}\right]-k_{T E N}^{+}\left[\mathrm{VIIIa}^{m}\right]\left[\mathrm{IXa}^{m}\right]
$$$$
+k_{T E N}^{-}\left[\mathrm{VIIIa}^{m}: \mathrm{IXa}^{m}\right] \text {. }
$$

$$
G_{\mathrm{VIIII}^{m}: \mathrm{IXa}^{m}}=k_{T E N}^{+}\left[\mathrm{VIIIa}^{m}\right]\left[\mathrm{IXa}^{m}\right]-k_{T E N}^{-}\left[\mathrm{VIIIa}^{m}: \mathrm{IXa}^{m}\right] .
$$

$$
\begin{gathered}
G_{\mathrm{V}}=-\frac{k_{5}[\mathrm{IIa}][\mathrm{V}]}{K_{5 M}+[\mathrm{V}]}-k_{5}^{+} N_{5}[\mathrm{AP}][\mathrm{V}]+k_{5}^{-}\left[\mathrm{V}^{m}\right] \\
G_{\mathrm{Va}}=\frac{k_{5}[\mathrm{IIa}][\mathrm{V}]}{K_{5 M}+[\mathrm{V}]}-k_{5}^{+} N_{5}[\mathrm{AP}][\mathrm{Va}]+k_{5}^{-}\left[\mathrm{Va}^{m}\right]-h_{5}[\mathrm{Va}] .
\end{gathered}
$$

$$
\begin{gathered}
G_{\mathrm{V}^{m}}=-\frac{k_{5}^{m}\left[\mathrm{IIa}^{m}\right]\left[\mathrm{V}^{m}\right]}{K_{5 M}^{m}+\left[\mathrm{V}^{m}\right]}-\frac{k_{5 t}^{m}\left[\mathrm{Xa}^{m}\right]\left[\mathrm{V}^{m}\right]}{K_{5 t M}^{m}+\left[\mathrm{V}^{m}\right]} \\
+k_{5}^{+} N_{5}[\mathrm{AP}][\mathrm{V}]-k_{5}^{-}\left[\mathrm{V}^{m}\right] \\
G_{\mathrm{Va}^{m}}=\frac{k_{5}^{m}\left[\mathrm{IIa}^{m}\right]\left[\mathrm{V}^{m}\right]}{K_{5 M}^{m}+\left[\mathrm{V}^{m}\right]}+\frac{k_{5 t}^{m}\left[\mathrm{Xa}^{m}\right]\left[\mathrm{V}^{m}\right]}{K_{5 t M}^{m}+\left[\mathrm{V}^{m}\right]}-k_{\mathrm{PRO}}^{+}\left[\mathrm{Xa}^{m}\right]\left[\mathrm{Va}^{m}\right] \\
+k_{\mathrm{PRO}}^{-}\left[\mathrm{Xa}^{m}: \mathrm{Va}^{m}\right]+k_{5}^{+} N_{5}[\mathrm{AP}][\mathrm{Va}]-k_{5}^{-}\left[\mathrm{Va}^{m}\right] \\
G_{\mathrm{Xa}^{m}: \mathrm{Va}}{ }^{m}= \\
k_{\mathrm{PRO}}^{+}\left[\mathrm{Xa}^{m}\right]\left[\mathrm{Va}^{m}\right]-k_{\mathrm{PRO}}^{-}\left[\mathrm{Xa}{ }^{m}: \mathrm{Va}^{m}\right] \\
G_{I}=-\frac{k_{f}([\mathrm{IIa}])[\mathrm{I}]}{K_{f M}+[\mathrm{I}]} \\
G_{\mathrm{Ia}}=\frac{k_{f}([\mathrm{IIa}])[\mathrm{I}]}{K_{f M}+[\mathrm{I}]} . \\
G_{\mathrm{TFPI}}=- \\
h_{10}^{T P+}[\mathrm{Xa}][\mathrm{TFPI}]+h_{10}^{T P-}[\mathrm{Xa}: \mathrm{TFPI}] \\
G_{\mathrm{Xa}: \mathrm{TFPI}}= \\
h_{10}^{T P+}[\mathrm{Xa}][\mathrm{TFPI}]-h_{10}^{T P-}[\mathrm{Xa}: \mathrm{TFPI}] \\
-h_{7}^{T P}[\mathrm{TF}: \mathrm{VIIa}][\mathrm{Xa}: \mathrm{TFPI}]
\end{gathered}
$$

\section{Appendix 2: Description of reactions}

Generation and depletion of factors VIIa, VII:

Tissue Factor (TF), an integral membrane protein gets exposed to blood upon blood vessel injury. It binds clotting factor VII/VIIa present in the plasma. Free, and tissue factor-bound factor VII is activated by factors IIa and Xa [51]. The TF-VIIa complex initiates the "extrinsic pathway" of blood coagulation. Clot formation proceeds by activation of zymogens factor IX and factor X [52]. TFPI exhibits a Xa-dependent inhibition of TF-VIIa [19].

\section{Generation and depletion of factors IXa, IX:}

While activation of factor IX by the tissue factor-factor VIIa complex is predominant and requires a membrane surface, that by factor XI is also important and is independent of a membrane surface [21, 53]. However, since we assume that the intrinsic pathway is inhibited, we neglect the role of factor $\mathrm{XI}$ in the present model. Inactivation of the activated factor IX occurs by the action of ATIII in the plasma [37, 54].

\section{Generation and depletion of factors Xa, X:}

Activation of factor $\mathrm{X}$ occurs by the tissue factor-factor VIIa complex, i.e., the extrinsic tenase complex (via 
extrinsic pathway), and by the factor VIIIa-factor IXa complex, i.e., the intrinsic tenase complex (via intrinsic pathway). Activated factor $X$ then combines with activated factor $\mathrm{V}$ to form the platelet membrane-bound prothrombinase complex [12, 55]. Following the inactivation of factor $\mathrm{Va}$ (in the prothrombinase complex) by APC, dissociation of factor $\mathrm{Xa}$ from the membrane surface occurs. The dissociated factor $\mathrm{Xa}$ is then removed by flow and/or inactivated by ATIII and TFPI in plasma [56].

\section{Generation and depletion of factors IIa, II:}

Activation of the zymogen prothrombin to the enzyme thrombin occurs predominantly by the action of prothrombinase on activated membrane surface [20]. However, small amounts of prothrombin are also activated in plasma at a low rate by factor $\mathrm{Xa}$ [10]. Thrombin is primarily inhibited by ATIII [37].

\section{Generation and depletion of activated and resting platelets:}

The tissue factor and collagen exposed due to disruption of sub-endothelium lead to activation of platelets. In addition to converting fibrinogen to fibrin, thrombin plays a major role in activating platelets [12, 57]. Also, platelets are constitutively activated once they come in contact with other activated platelets in the plasma or on the sub-endothelial surface [57].

\section{Generation and depletion of factors VIIIa, VIII:}

Thrombin-activation of factor VIII does not necessarily require a membrane surface. However, activation of factor VIII by activated factor $\mathrm{X}$, which is also an important reaction, requires activated platelets [58, 59]. On being activated, factor VIII shows cofactor activity in conjunction with activated factor IX [21]. Inhibition of activated factor VIII occurs due to the proteolytic attack by activated protein $\mathrm{C}$ (APC) on the membrane surface, apart from spontaneous decay [60].

\section{Formation and dissociation of intrinsic tenase complex $\left(\mathrm{VIIIa}^{m}: \mathrm{IXa}^{m}\right)$ :}

On activation, activated factor IX combines with its active cofactor, factor VIIIa, and forms intrinsic tenase complex on the surface of activated platelets. This procoagulant complex then activates factor $\mathrm{X}$ via the intrinsic pathway $[21,25]$.
Generation and depletion of factor $V a, V$ :

Activation of factor $\mathrm{V}$ to its cofactor state, factor Va, occurs by the action of thrombin [7], as well as by that of factor Xa (on the membrane surface) [61]. Competitive binding of APC to factor $\mathrm{Va}$ (which we have not included) followed by cleavage leads to inactivation of factor Va [62], apart from spontaneous decay just like factor VIIIa.

\section{Formation and dissociation of prothrombinase complex $\left(\mathrm{Xa}^{m}: \mathrm{Va}^{m}\right)$ :}

Factor $\mathrm{Va}$, the cofactor of factor $\mathrm{Xa}$, binds it on the platelet membrane surface giving rise to the prothrombinase complex which converts prothrombin to thrombin [55, 62].

\section{Generation and depletion of ATIII and TFPI:}

While ATIII is a major physiologic inhibitor of almost all serine proteases produced during the process of blood coagulation process, TFPI mainly targets factor Xa and the TF-VIIa-factor Xa complex. Heparin-catalyzed ATIII-inhibition of factors IX, X and II is faster than the uncatalyzed reaction [54]. Since heparin is released from endothelial cells upon injury, in our case, we assume that the amount of heparin present is negligible as endothelial cells are not present in plasma in vitro. Inactivation by ATIII and TFPI occurs once the clotting enzymes escape into the plasma from the site of thrombus formation [20].

\section{References}

[1] Luan D, Zai M and Varner J D 2007 Computationally derived points of fragility of a human cascade are consistent with current therapeutic strategies. PLoS Comput. Biol. 3(7): e142

[2] Panteleev M A, Sveshnikova A N, Belyaev A V, Nechipurenko D Y, Gudich I, Obydenny S I, Dovlatova N, Fox S C and Holmuhamedov E L 2014 Systems biology and systems pharmacology of thrombosis. Math. Model. Nat. Phenom. 9(6): 4-16

[3] Mann K G 2012 Is there value in kinetic modeling of thrombin generation? yes. J. Thromb. Haemost. 10(8): 1463-1469

[4] Bates S M and Weitz J I 2005 Coagulation assays. Circulation 112(4): e53-e60

[5] Walenga J M and Hoppensteadt D A 2004 Monitoring the new antithrombotic drugs. In: Seminars in thrombosis and hemostasis, vol. 30, pp. 683-695. Thieme Medical, New York, USA

[6] Ataullakhanov F I and Panteleev M A 2005 Mathematical modeling and computer simulation in blood coagulation. Pathophys. Haemost. Thromb. 34(2-3): 60-70 
[7] Monroe D M, Hoffman M and Roberts H R 2002 Platelets and thrombin generation. Arterioscler. Thromb. Vasc. Biol. 22: $1381-1389$

[8] Kuharsky A L and Fogelson A L 2001 Surface-mediated control of blood coagulation: the role of binding site densities and platelet deposition. Biophys. J. 80(3): 1050-1074

[9] Fogelson A L, Hussain Y H and Leiderman K 2012 Blood clot formation under flow: the importance of factor $\mathrm{xi}$ depends strongly on platelet count. Biophys. J. 102(1): 10-18

[10] Hockin M F, Jones K C, Everse S J and Mann K G 2002 A model for the stoichiometric regulation of blood coagulation. J. Biol. Chem. 277(21): 18322-18333

[11] Anand M, Rajagopal K and Rajagopal K R 2008 A model for the formation, growth, and lysis of clots in quiescent plasma: a comparison between the effects of antithrombin iii deficiency and protein c deficiency. J. Theor. Biol. 253(4): 725-738

[12] Furie B and Furie B C 2008 Mechanisms of thrombus formation. N. Eng. J. Med. 359(9): 938-949

[13] Monroe D M and Hoffman M 2006 What does it take to make the perfect clot? Arterioscler. Thromb. Vasc. Biol. 26(1): 41-48

[14] Jesty J 2001 Blood coagulation. Wiley, New York

[15] Tracy P B, Eide L L, Bowie E J, Mann K G and Tracy B 1982 Radioimmunoassay of factor $\mathrm{V}$ in human plasma and platelets. Blood 60: 59-63

[16] Lipscomb M S and Walsh P N 1979 Human platelets and factor xi: localization in platelet membranes of factor xi-like activity and its functional distinction from plasma factor xi. J. Clin. Invest. 63(5): 1006

[17] Wood J P, Silveira J R, Maille N M, Haynes L M and Tracy P B 2011 Prothrombin activation on the activated platelet surface optimizes expression of procoagulant activity. Blood 117(5): 1710-1718

[18] van't Veer C and Mann K G 1997 Regulation of tissue factor initiated thrombin generation by the stoichiometric inhibitors tissue factor pathway inhibitor, antithrombin-iii, and heparin cofactor-ii. J. Biol. Chem. 272(7): 4367-4377

[19] Panteleev M A, Zarnitsina V I and Ataullakhanov F I 2002 Tissue factor pathway inhibitor. Eur. J. Biochem. 269(8): 2016-2031

[20] Butenas S and Mann K G 2002 Blood coagulation. Biochemistry (Moscow) 67(1): 3-12

[21] Hoffman R, Benz E J, Silberstein L E, Heslop H, Weitz J and Anastasi J 2012 Hematology: basic principles and practice, expert consult premium edition-Enhanced online features. Elsevier, Amsterdam

[22] Diamond S L 2013 Systems biology of coagulation. J. Thromb. Haemost. 11(s1): 224-232

[23] Chatterjee M S, Denney W S, Jing H and Diamond S L 2010 Systems biology of coagulation initiation: kinetics of thrombin generation in resting and activated human blood. PLoS Comput. Biol. 6(9): e1000950

[24] Jones K C and Mann K G 1994 A model for the tissue factor pathway to thrombin. J. Biol. Chem. 269(37): 23367-23373

[25] Mann K G, Butenas S and Brummel K 2003 The dynamics of thrombin formation. Arterioscler. Thromb. Vasc. Biol. 23(1): $17-25$

[26] Lourens Marcel A J 2007 A mathematical model for platelet adhesion and activation. Master thesis

[27] Tokarev A, Sirakov I, Panasenko G, Volpert V, Shnol E, Butylin A and Ataullakhanov F 2012 Continuous mathematical model of platelet thrombus formation in blood flow. Russian J. Numer. Anal. Math. Model. 27(2): 191-212

[28] Ataullakhanov F I, Krasotkina Yu V, Sarbash V I, Volkova R I, Sinauridse E I and Kondratovich A Yu 2002 Spatiotemporal dynamics of blood coagulation and pattern formation: an experimental study. Int. J. Bifurc. Chaos 12(09): 1969-1983

[29] Ataullakhanov F I, Zarnitsina V I, Pokhilko A V, Lobanov A I and Morozova O L 2002 Spatio-temporal dynamics of blood coagulation and pattern formation: a theoretical approach. Int. J. Bifurc. Chaos 12(09): 1985-2002

[30] Moiseyev G, Givli S and Bar-Yoseph P Z 2013 Fibrin polymerization in blood coagulationa statistical model. $J$. Biomech. 46(1): 26-30

[31] Orfeo T, Butenas S, Brummel-Ziedins K E and Mann K G 2005 The tissue factor requirement in blood coagulation. $J$. Biol. Chem. 280(52): 42887-42896

[32] Balandina A N, Shibeko A M, Kireev D A, Novikova A A, Shmirev I I, Panteleev M A and Ataullakhanov F I 2011 Positive feedback loops for factor $\mathrm{v}$ and factor vii activation supply sensitivity to local surface tissue factor density during blood coagulation. Biophys. J. 101(8): 1816-1824

[33] Beard Daniel A 2012 Biosimulation: simulation of living systems. Cambridge University Press, Cambridge.

[34] Rand M D, Lock J B, Van't Veer C, Gaffney D P and Mann K G 1996 Blood clotting in minimally altered whole blood. Blood 88(9): 3432-3445

[35] Lawson J H, Butenas S and Ribarik N 1993 Complex-dependent inhibition of factor VIIa by antithrombin III and Heparin. J. Biol. Chem. 268(2): 767-770

[36] Mann K G, Nesheim M E, Church W R, Haley P and Krishnaswamy S 1990 Surface-dependent reactions of the vitamin k-dependent enzyme complexes. Blood 76(1): 1-16

[37] Wiebe E M, Stafford A R, James C, Weitz J I and Fredenburgh J C 2003 Enzyme catalysis and regulation: mechanism of catalysis of inhibition of factor IXa by antithrombin in the presence of heparin or pentasaccharide mechanism of catalysis of inhibition of factor IXa by antithrombin in the presence of heparin or pentasaccharide. J. Biol. Chem. 278(37): 35767-35774

[38] Krishnaswamy S, Jones K C and Mann K G 1988 Prothrombinase complex assembly. kinetic mechanism of enzyme assembly on phospholipid vesicles. J. Biol. Chem. 263(8): 3823-3834

[39] Raut S, Weller L and Barrowcliffe T W 1999 Phospholipid binding of factor viii in different therapeutic concentrates. Br. J. Haematol. 107(2): 323-329

[40] Anand M, Rajagopal K and Rajagopal K R 2003 A model incorporating some of the mechanical and biochemical factors underlying clot formation and dissolution in flowing blood. J. Theor. Med. 5(3-4): 183-218

[41] Ahmad S S, Rawala-Sheikh R and Walsh P N 1989 Comparative interactions of factor ix and factor ixa with human platelets. J. Biol. Chem. 264(6): 3244-3251

[42] Ahmad S S, Scandura J M and Walsh P N 2000 Structural and functional characterization of platelet receptor-mediated factor viii binding. J. Biol. Chem. 275(17): 13071-13081

[43] Butenas S, van't Veer C and Mann K G 1999 Normal thrombin generation. Blood 94(7): 2169-2178

[44] Marx R E 2001 Platelet-rich plasma (PRP): what is PRP and what is not PRP? Implant Dent. 10(4): 225-228 
[45] Sultan A 2010 Five-minute preparation of platelet-poor plasma for routine coagulation testing. East. Mediterr. Health J. 16(2): 233-236

[46] Danforth C M, Orfeo T, Mann K G, Brummel-Ziedins K E and Everse S J 2009 The impact of uncertainty in a blood coagulation model. Math. Med. Biol. 26(4): 323-336

[47] Naidu P P and Anand M 2014 Importance of viiia inactivation in a mathematical model for the formation, growth, and lysis of clots. Math. Model. Nat. Phenom. 9(06): 17-33

[48] Hemker H C and Ataullakhanov F I 2005 Good mathematical practice: simulation of the hemostatic-thrombotic mechanism, a powerful tool but one that must be used with circumspection. Pathophys. Haemost. Thromb. 34(2-3): $55-57$

[49] Butenas S, Cawthern K M, van't Veer C, DiLorenzo M E, Lock J B and Mann K G 2001 Antiplatelet agents in tissue factor-induced blood coagulation. Blood 97(8): 2314-2322

[50] Sequeira A and Bodnár T 2014 Blood coagulation simulations using a viscoelastic model. Math. Model. Nat. Phenom. 9(6): 34-45

[51] Butenas S and Mann K G 1996 Kinetics of human factor VII activation. Biochemistry 35(6): 1904-1910

[52] Butenas S, Orfeo T and Mann K G 2009 Tissue factor in coagulation which? where? when? Arterioscler. Thromb. Vasc. Biol. 29(12): 1989-1996

[53] Bauer K A, Kass B L, ten Cate H, Hawiger J J and Rosenberg R D 1990 Factor ix is activated in vivo by the tissue factor mechanism. Blood 76(4): 731-736

[54] Pieters J, Willems G, Hemker H C and Lindhout T 1988 Inhibition of factor LXa and factor X, by antithrombin III/ heparin during factor X activation. J. Biol. Chemi. 263(30): 15313-15318

[55] Krishnaswamy S, Williams E B and Mann K G 1986 The binding of activated protein $\mathrm{C}$ to factors $\mathrm{V}$ and Va. J. Biol. Chem. 261(21): 9684-9693

[56] van't Veer C, Hackeng T M, Delahaye C, Sixma J J and Bouma B N 1994 Activated factor X and thrombin formation triggered by tissue factor on endothelial cell matrix in a flow model: effect of the tissue factor pathway inhibitor. Blood 84: 1132-1142

[57] Heemskerk J W M, Bevers E M and Lindhout T 2002 Platelet activation and blood coagulation. Thromb. Haemost. Stuttgart. 88(2): 186-194

[58] Neuenschwander P F and Jesty J 1988 A comparison of phospholipid and platelets in the activation of human factor VIII by thrombin and factor $\mathrm{Xa}$, and in the activation of factor X. Blood 72(5): 1761-1770

[59] Fay P J 2004 Activation of factor viii and mechanisms of cofactor action. Blood Rev. 18(1): 1-15

[60] Neuenschwander P F and Jesty J 1992 Thrombin-activated and factor xa-activated human factor viii: differences in cofactor activity and decay rate. Arch. Biochem. Biophys. 296(2): 426-434

[61] Monkovic D D and Tracy P B 1990 Activation of human factor V by factor Xa and thrombin. Biochemistry 29(5): $1118-1128$

[62] Mann K G 2003 Thrombin formation. CHEST J. 124(3 Suppl): 4S-10S 